\title{
Pancreatic Intraepithelial Neoplasia-1A
}

National Cancer Institute

\section{Source}

National Cancer Institute. Pancreatic Intraepithelial Neoplasia-1A. NCI Thesaurus. Code C95429.

A pancreatic intraepithelial neoplasia characterized by the presence of tall columnar cells that form flat architectural patterns. Mild cytological atypia is present. 